\title{
Reflexões sobre interdisciplinaridade, interculturalidade e interinstitucionalidade em processo formativo de professores indígenas ${ }^{1}$
}

\author{
Reflections on interdisciplinarity, interculturality and \\ interinstitutionality in a training process of indigenous \\ teachers
}

Beatriz Osorio Stumpf ${ }^{2}$

DOI: 10.20435/tellus.v19i38.583

\begin{abstract}
Resumo: $\mathrm{O}$ artigo apresenta reflexões sobre interdisciplinaridade, interculturalidade e interinstitucionalidade na formação continuada de professores indígenas, com base em atuação desenvolvida com etnias indígenas de recente contato do alto rio Negro, AM. A análise do processo de construção e de desenvolvimento dessa experiência revela a importância de ações interculturais, visando à valorização cultural e instrumentalização para lidar com exigências da sociedade ocidental. A articulação entre várias instituições e áreas de conhecimento mostra contribuições relevantes para diversas dimensões envolvidas na questão, incluindo aspectos pedagógicos, organizacionais, relacionais e econômicos. Um enfoque maior é direcionado para a relação entre educação e antropologia, mostrando sua complementaridade nesse tipo de atuação.
\end{abstract}

Palavras-chave: interdisciplinaridade; interculturalidade; formação de professores indígenas.

\begin{abstract}
The article presents reflections on interdisciplinarity, interculturality and interinstitutionality in the continuing formation of indigenous teachers, based on the work developed with indigenous ethnic groups of recent contact in Amazonas. The analysis of its process of construction and development reveals the importance of intercultural actions for cultural appreciation and instrumentalization to deal with the demands of Western society. The articulation between diverse institutions and areas of knowledge shows relevant contributions to several dimensions involved in the question, including pedagogical, organizational, relational and economic aspects. A greater focus is
\end{abstract}

${ }^{1}$ O presente trabalho foi realizado com apoio da Coordenação de Aperfeiçoamento de Pessoal de Nível Superior - Brasil (CAPES) - Código de Financiamento 001.

2 Universidade Federal de Santa Cruz do Sul (UNISC), Santa Cruz do Sul, Rio Grande do Sul, Brasil. 
directed towards the relation between education and anthropology, showing its complementarity in this type of action.

Keywords: interdisciplinarity; interculturality; training of indigenous teachers.

\section{INTRODUÇÃO}

O artigo oferece uma reflexão sobre interculturalidade, interdisciplinaridade e atuação interinstitucional na formação continuada de professores indígenas, a partir de processo formativo desenvolvido no alto rio Negro, em São Gabriel da Cachoeira, AM, com etnias indígenas de recente contato, ou seja, grupos indígenas que apresentam especificidades em sua relação com a sociedade nacional e alto grau de autonomia na relação com o Estado (FUNAl, 2012).

A experiência contou com a participação de um conjunto de instituiç̧̃es e profissionais de diferentes áreas de conhecimento, abrangendo indígenas e não indígenas, proporcionando elementos significativos para esse tipo de discussão. A atuação foi realizada através do projeto de extensão "Programa de Formação Continuada: Fortalecendo Escolas Indígenas Hupd'äh, Yuhupdëh e Dâw", do Instituto Federal do Amazonas (IFAM), Campus São Gabriel da Cachoeira / Núcleo Gestor de Estudos Linguísticos e Antropológicos (NUGLAN), em parceria com a Secretaria Municipal de Educação e Cultura de São Gabriel da Cachoeira (SEMEC), a Fundação Nacional do Índio (FUNAI) e a Federação das Organizações Indígenas do Rio Negro (FOIRN), organização criada em 1987 como resultado do movimento pela demarcação de uma terra indígena contínua, a qual tem por objetivo a defesa dos direitos coletivos dos povos indígenas da região.

O texto inicia com uma contextualização, de modo a caracterizar as especificidades da região, bem como das etnias envolvidas no trabalho, com sua situação atual de vida e de relação com a sociedade, e mais especificamente no que tange à educação escolar. Na medida em que esse quadro é apresentado, vai se delineando o problema de pesquisa, o qual se refere à situação de povos indígenas de recente contato que estão se aproximando de centros urbanos, atraídos por benefícios sociais e pela possibilidade de consumo de produtos industrializados. Sem preparação e orientação, vão sofrendo impactos das armadilhas da cidade, com graves consequências como doenças, erosão cultural, violência e exploração. A questão que emerge a partir desse conjunto de situações é de que modo 
a formação de professores indígenas pode se constituir para que possa lidar com essa problemática.

A partir desse panorama, são trazidas informações sobre a construção e o desenvolvimento do projeto de formação continuada que proporcionou a reflexão, concentrando-se no período de 2015 e 2016, no qual a atuação foi integrada a projeto de pesquisa, através do IFAM, Campus São Gabriel da Cachoeira. O contexto é também utilizado como base para a discussão subsequente, que versa sobre interinstitucionalidade, interculturalidade/interetnicidade, e interdisciplinaridade, tecendo reflexões a partir do destaque desses aspectos na elaboração e concretização da formação. Na interdisciplinaridade, é destinado um olhar especial para a relação entre antropologia e educação, áreas que se evidenciaram como essenciais na trajetória investigada.

Uma abordagem parcial desse trabalho foi apresentada na XII Anped Sul (Reunião Científica Regional da Associação Nacional de Pós-Graduação e Pesquisa em Educação), em julho de 2018. O texto aqui exposto mostra uma versão ampliada, oferecendo mais elementos contextuais, referenciados por diversos/as pesquisadores/as dessas etnias, e contemplando uma reflexão mais ampla e profunda, com o acréscimo de elementos importantes, principalmente no que tange a aspectos pedagógicos e investigativos.

\section{CONTEXTUALIZAÇÃO}

O cenário deste trabalho se refere a São Gabriel da Cachoeira, um município situado no interior do Amazonas, região do alto rio Negro, no extremo oeste do país, fronteira com Colômbia e Venezuela. É o município do Brasil com maior predominância indígena, onde três línguas ameríndias são oficializadas, além do português. Nessa região, vivem vinte e três povos indígenas, pertencentes a quatro famílias linguísticas: Tukano Oriental, Aruák, Yanomami e Maku.

A unidade linguística "Maku", de acordo com Athias (2009), agrega basicamente seis povos: Nukak e Kakwa na Colômbia; e Hupd'äh, Yuhupideh, Dâw e Naböb no Brasil, sendo que as etnias Hupd'äh, Yuhupideh e Dâw habitam a região do alto rio Negro, constituindo o público do projeto que é base para essa reflexão. Recentemente, algumas iniciativas têm se voltado para a mudança do nome dessa família linguística na busca de um substituto para o termo "Maku", considerando 
seu conteúdo pejorativo e o fato de não ter sua legitimidade reconhecida pelas próprias populações que são assim designadas. A palavra Maku significa "aquele que não tem língua" ou "aquele que não sabe nossa língua", sendo a denominação dada pelos Tukano para se referir a esses povos. Epps (2005) propõe o termo "Nadawhup" para a família composta pelos Maku da área brasileira, o qual é utilizado neste artigo, apesar de ainda estar em discussão.

Segundo Ramirez (2006), todos os grupos da região do rio Negro que fazem parte dessa família linguística vivem no interior da floresta, nos pequenos igarapés, diferente de outras etnias que povoam as margens de rios maiores. Os Hupd'äh habitam a região interfluvial do rio Tiquié e rio Papuri, afluentes da margem esquerda do rio Uaupés na região do alto rio Negro. Atualmente estão distribuídos em mais ou menos 35 comunidades, estimados em um total de 1.500 indivíduos. Cabalzar e Ricardo (1998) descrevem os Hupd'äh como o povo Nadawhup com maior população, sendo Dâw o grupo atualmente menos numeroso, o qual habita o rio Negro nas proximidades da cidade de São Gabriel da Cachoeira, na sua margem oposta. E os Yuhupdeh vivem nos afluentes ao sul do rio Tiquié, no rio Apapóris e no seu afluente Traíra.

Conforme Athias (2009), as formas adaptativas dos grupos Nadawhup contrapõem-se ao modelo de ocupação espacial dos Arawak e Tukano, os quais possuem orientação, ciclo de vida e desenvolvimento tecnológico direcionado para o rio. Os Nadawhup, por habitarem preferencialmente os pequenos igarapés no interior da mata, apresentam um modo de vida orientado para a floresta e utilizam uma tecnologia adaptada aos recursos desse ecossistema, tendo desenvolvido estratégias eficazes de sobrevivência, totalmente integradas a esse ambiente. Os Hupd'äh trazem conhecimentos ecológicos de grande importância, como saberes sobre o funcionamento da floresta, conhecimento dos frutos, peixes, insetos e outros tipos de carne sem sangue, indicadores climáticos, comportamento animal, diferentes espécies de abelhas e tipos de mel (SILVERWOOD-COPE, 1990 p. 28-57). Além disso, segundo informações de Monteiro (2011, p. 144), ainda mantêm suas tradições e especificidades culturais, como rituais, benzimentos e saberes sobre plantas de poder. Marques (2009) observa que outras etnias buscam benzimentos dos Hupd'äh, trocando por objetos e alimentos. 
No entanto, atualmente, esses povos frequentam muito a sede do município, principalmente em busca de benefícios sociais, sem possuir ainda os conhecimentos necessários para circular no meio urbano, como o domínio da língua portuguesa e do modo de lidar com dinheiro, cartões bancários e documentos. Essa questão, aliada à falta de estrutura adequada para sua recepção e manutenção na cidade, tem ocasionado o envolvimento em uma série de problemas, como doenças, uso abusivo de álcool, endividamento, exploração por parte de comerciários, acidentes e alto índice de suicídio. Esses indígenas chegam a permanecer vários meses acampados para resolver seus problemas, muitas vezes sem recursos para retornar a suas comunidades. Geralmente ficam em local próximo à cidade, conhecido como "beiradão", uma área na margem do rio Negro, com grande incidência de malária, diarreia e outras doenças, sem infraestrutura sanitária adequada, acesso à água potável e coleta de resíduos sólidos.

Silva (2017) descreve detalhadamente diversas situações problemáticas, com relação às dificuldades enfrentadas pelos Hupd'äh na cidade, caracterizando a burocracia e os modos de funcionamento das instituições responsáveis pela emissão de documentos e outras ações relacionadas com benefícios sociais.

\subsection{Histórico e situação atual da educação escolar dessas etnias}

De acordo com Athias (2009), ainda é muito recente o contato dos Hupd'äh com a sociedade brasileira e mais especificamente com a instituição escolar, a qual foi introduzida na região do alto rio Negro pelos missionários católicos em 1916. Essa etnia teve acesso à educação escolarizada somente em 1978, através de colégios em comunidades Tukano. As escolas em aldeias Hupd'äh iniciaram apenas a partir de 1996, em um processo semelhante ao dos Tukano, o qual tende a reproduzir o modelo missionário.

Silverwood-Cope (1990, p. 28) cita as etnias Nadawhup como as que menos se adaptaram à escola imposta pelos Salesianos, descrevendo alguns relatos de situações de fuga. No entanto, atualmente, esses povos têm buscado a educação escolar. Marques (2015, p. 78) destaca o desejo de representantes do povo Hupd'äh de que seus filhos estudem como um dos motivos para se fixarem em aglomerados maiores, cuja permanência tem sérias consequências em termos de escassez alimentar e conflitos sociais. 
A escola é como um elo entre o passado feliz onde a cultura, pautada na reciprocidade, garantia o modo de vida e cosmologia dos Hupd'äh, e um presente onde é necessário buscar melhorar a agricultura, a caça, a pesca, a coleta, o saneamento, a saúde e a valorização da própria cultura como formas de melhorar a qualidade de vida dos Hupd'äh. (PAIVA, 2010, p. 78).

A instituição escolar também é referida por Monteiro (2011, p. 35, 80) como um dos elementos citados por membros da etnia Hupd'äh com relação à "vida civilizada", inclusive influenciando nos casamentos, conforme depoimento de representante dessa etnia, de que o casamento com Tucano ou com branco tende a ocorrer com aqueles que estudam mais. E Lima et al. (2016, p. 219) apresentam resultados de oficinas do Plano de Gestão Territorial e Ambiental (PGTA) desenvolvidas com comunidades Hupd'äh e Youhupdeh, mostrando suas reivindicações, as quais incluem educação escolar diferenciada e atendimento de saúde específico.

Sendo a escola um elemento que está sendo buscado, mesmo por etnias de recente contato, torna-se necessário um grande cuidado na sua implementação, de forma a evitar impactos negativos em termos de perdas de saberes tradicionais e de modos de vida adaptados ao ambiente. Nessa direção, Lasmar (2005, p. 262) destaca a importância da escola diferenciada para cada etnia, conforme suas especificidades.

Essa educação escolar indígena específica tem sido uma das importantes discussões e ações do movimento indígena regional, através da FOIRN, em um processo de construção de escolas diferenciadas, interculturais e bilíngues, próprias de cada etnia e de acordo com as características e interesses das comunidades. Com relação a essa trajetória, as escolas indígenas da região se encontram em diferentes estágios de construção, consolidação e reconhecimento legal, estando algumas em fase inicial de elaboração e funcionamento, enquanto outras constituem exemplos inovadores de educação indígena diferenciada para o país, como as escolas Tuyuka, Baniwa, Wanano, Tukano e Tariano, que possuem currículos, programas, materiais e métodos adaptados à cultura e ao ritmo de vida das comunidades. A estruturação das escolas indígenas na região também já avançou para a elaboração de proposta de ensino superior diferenciado, através do Programa de Formação Avançada, construído coletivamente a partir de processo de consulta, com a realização de seminários e reuniões (BARRETTO FILHO, 2012). 
No entanto, as escolas dos povos Nadawhup não estão acompanhando essa trajetória e ainda apresentam diversos problemas estruturais, falta de materiais, escassa formação específica e assessoria para a criação de Projeto Político Pedagógico. De acordo com o registro de visitas realizadas pela FUNAI em estabelecimentos escolares do rio Tikié, as escolas das etnias Hupd'äh e Yuhupdeh funcionam em locais muito precários, construções feitas pelas comunidades para serem centros de reuniões e festas, apenas com bancos no entorno de um círculo coberto de palha. Os telhados se encontram em péssimas condições, com muitos buracos, permitindo a constante penetração de sol e chuva e provocando maiores dificuldades no desenvolvimento das atividades escolares, bem como nas ações de manutenção das construções. São raras as cadeiras e mesas, sendo que as lousas são mais frequentes, mas estão apoiadas no chão e submetidas às intempéries. Não existem armários e depósitos para guardar materiais e merenda, que ficam no chão, em prateleiras improvisadas ou sacos de fibra. Esse registro manifesta ainda que não houve discussão e elaboração de projeto político pedagógico em nenhuma escola. Não há acompanhamento pedagógico aos professores, os quais ficam confusos em relação ao que ensinar e de que maneira, não conseguindo aproveitar os livros enviados para as escolas. Mesmo os alunos do 30 ano mal sabem ler ou escrever algumas palavras. As atividades quase sempre são desenhos com palavras ou frases copiadas, denotando que possivelmente haja confusão entre os conceitos de cópia e entendimento do sistema alfabético.

Poucos esforços estão sendo realizados para a construção de uma escola adequada às características dessas etnias. O relato de um representante Hupd'äh, trazido por Monteiro (2010, p. 111), salienta que a ideia de uma educação específica para seu povo teve início através da assessoria da organização "Saúde sem Limites", com o projeto "Saúde e Educação entre os Hupd'äh". A autora declara que anteriormente os Hupd'äh nunca haviam sido consultados com relação à construção de uma escola de acordo com suas especificidades.

Diante dessas considerações, destaca-se a relevância de processos específicos de formação de professores para as etnias Nadawhup, que proporcionem espaços de escuta e mediação de processos de construção e consolidação de suas escolas. De acordo com Monteiro e Mcllum (2013), as estratégias dos Hupd'äh que os possibilitam viver bem em seu território aliam-se muito à sazonalidade, 
no que se refere a atividades como o trabalho na roça e as inserções ao interior da mata. É importante que essa organização espacial e temporal, além de outros aspectos culturais específicos, esteja presente no calendário próprio da escola dessas etnias, bem como na sua organização curricular.

Além disso, conforme Marques (2009) existe uma inconstância dos povos Nadawhup em suas relações com regras em geral, em contraposição à relativa coerência entre o discurso e a prática Tukano, o que implica descrições dessas populações com características de fluidez e flexibilidade, em contraste a um "fundo de fixidez" estabelecido pelos demais povos da região. Uma educação escolar Nadawhup precisa ser construída de forma adaptada a essas características, com flexibilidade, respeitando suas relações sociais e modos de se relacionar com a natureza.

\subsection{O processo formativo: construção e desenvolvimento}

A iniciativa do Programa de Formação Continuada "Fortalecendo Escolas Indígenas Hupd'äh, Yuhup'dëh e Dâw" emergiu da convivência, diálogo e ações conjuntas entre representantes dessas etnias e profissionais de diferentes áreas de conhecimento, como antropologia, pedagogia, psicologia e assistência social, membros do Coletivo de apoio aos povos Yuhup'dëh e Hupd'äh (CAPYH). Trata-se de um grupo não institucionalizado que desenvolve ações de assessoria a esses povos em São Gabriel da Cachoeira, formado por pesquisadores/as dessas populações e profissionais de diferentes áreas que atuam ou atuaram diretamente com eles através de instituições acadêmicas, órgãos públicos e organizações não governamentais. Esse coletivo de profissionais realiza ações no "beiradão" com apoio aos indígenas acampados, além de contribuir com suporte a suas reivindicações políticas, incluindo a mediação com outras organizações e instituições.

O convívio emergiu da moradia temporária conjunta em uma residência, a qual também consistia em ponto de apoio para essas etnias quando vinham para a cidade, onde obtinham orientação e acompanhamento do grupo para resolver questões relacionadas com documentação e benefícios sociais. Através da convivência foi possível discutir sobre suas demandas, anseios, dificuldades e potencialidades, constituindo a base para a construção do projeto, o qual foi apresentado ao IFAM, através do Núcleo Gestor de Estudos Linguísticos e 
Antropológicos (NUGLAN), na forma de projeto de extensão, integrado a uma proposta de pesquisa. A investigação teve como base metodológica a pesquisa-ação, cujas vantagens para área da educação são abordadas por Engel (2000, p. 183), por ser uma pesquisa engajada, que integra teoria e prática, e busca alcançar um resultado funcional relevante para cada situação.

Foram construídas parcerias com SEMEC, FUNAI e FOIRN, por meio de reuniões que acompanharam todo o processo. A partir dos diálogos com a Secretaria de Educação, foi verificada a sua dificuldade em realizar o acompanhamento de todas as escolas das comunidades da região, devido às enormes distâncias, grande número de escolas e poucos profissionais e recursos. Essa instituição proporcionou materiais e profissionais para participação na formação, com escuta das demandas, explicações e informações. A FUNAI disponibilizou recursos para alimentação e combustível para o deslocamento dos professores. A FOIRN forneceu o local para o curso e cozinha para preparo das refeições. O IFAM propiciou professores de diversas áreas de conhecimento e uma parte do material.

Desde sua elaboração até a execução, essa atuação reflete uma visão de construção a partir das demandas, respeito aos hábitos e valores dessas etnias, relação com atores locais e um caráter multidimensional, envolvendo a integração entre diversas dimensões, como educação, saúde, assistência social, direito, política, economia e cultura, com o trabalho solidificado na articulação entre diferentes áreas de conhecimento, assim como na construção interinstitucional e intercultural, com participação de indígenas de variadas etnias e não indígenas.

O projeto tem como objetivo contribuir para o fortalecimento da Educação Escolar Indígena Diferenciada das etnias Nadawhup da região do alto rio Negro, através de formação continuada de professores. A estratégia da formação se fundamenta em um processo de diálogo intercultural, na forma de espaços de reflexão, construção e mediação para o fortalecimento de escolas indígenas diferenciadas, de acordo com as especificidades dessas etnias, conforme seus interesses, necessidades e estágios de desenvolvimento das escolas. As atividades são conduzidas de forma a possibilitar a expressão das demandas existentes, a partir das quais é continuamente construído e implementado o processo de formação, abrangendo assessoria pedagógica, subsídios e elementos de apoio. A abordagem envolve um conjunto diversificado de métodos, incluindo técnicas 
participativas, dinâmicas de grupo, atividades artísticas e culturais, vivências, elaboração de mapas, construção de materiais didáticos e exposições dialogadas com apresentação de imagens e filmes.

Devido às grandes distâncias das comunidades Hupd'äh e Yuhupdeh, as ações são centralizadas no município de São Gabriel da Cachoeira, proporcionando a troca interétnica de ideias e experiências entre os/as participantes, mas também contemplando atividades de construção organizadas na forma de grupos de trabalho, específicos para cada etnia. As etapas da formação são realizadas nos períodos de férias escolares, aproveitando a época em que muitos professores se encontram no município para resolver suas questões de documentação e contratação, contribuindo para o apoio a essa estada na cidade, oferecendo local de estadia, alimentação, atividades e orientações.

Desse modo, a formação continuada ocorre em um formato de ciclos semestrais, envolvendo um circuito de reflexão, ação e avaliação. A partir de subsídios teóricos, ilustrativos e práticos, junto a atividades reflexivas e construtivas, é proporcionada uma base para a ação dos/as professores/as em suas comunidades. A cada seis meses, são realizadas novas etapas de avaliação, formação e planejamento, em que os/as participantes apresentam seus resultados, dificuldades e avanços, possibilitando a troca de experiências, nas quais são sugeridos elementos para a ação docente.

Os programas são desenvolvidos com uma visão interdisciplinar e intercultural, reunindo teoria e prática, de forma conectada aos temas de interesse dos povos indígenas e das comunidades dessas etnias, principalmente no que se refere a território, ambiente, sustentabilidade, saúde, cultura e ética. Os assuntos estão organizados na forma de eixos temáticos conectados entre si. Esses eixos e seus respectivos conteúdos correspondem à integração entre as diversas áreas de conhecimento e temas transversais, conforme o Referencial Curricular Nacional para as Escolas Indígenas (BRASIL, 1988), documento elaborado com a participação de indígenas de diversas etnias brasileiras.

Durante as etapas de 2015 e 2016, foram trabalhados os seguintes eixos temáticos: "Pedagogia Intercultural”; "Alfabetização, Letramento e Literatura Multilíngue"; "Etnomatemática, Matemática e Numeramento"; "Pluralidade Cultural”; "Direitos, Lutas e Movimentos"; "Terra, Conservação da Biodiversidade e Auto-sustentação"; 
"Educação e Relação com Sociedade". Os eixos "Alfabetização, Letramento e Literatura Multilíngue" e "Etnomatemática, Matemática e Numeramento" foram repetidos, por solicitação dos/as participantes durante a avaliação da primeira etapa. A repetição desses eixos foi realizada com a produção de novas versões, elaboradas de modo a oferecer outros tipos de subsídios e atividades, proporcionando o aprofundamento de conhecimentos, exercícios e produção de materiais.

\section{DISCUSSÃO}

\subsection{Interinstitucionalidade}

A complexidade da questão indígena exige uma maior integração e articulação entre diversas instituições, principalmente diante da criticidade do momento atual, de criminalização de movimentos sociais e acusações contra organizações não governamentais e universidades.

No entanto as estruturas institucionais e pedagógicas são estabelecidas em padrões de divisão, classificação e hierarquização de saberes e funções. Os modelos institucionais são fundamentados no pensamento ocidental, com sistemas extremamente burocráticos, muito diferentes da lógica indígena e de suas demandas, e distantes de suas realidades, principalmente no que se refere a etnias de recente contato, dificultando as ações e podendo gerar apatia e sentimentos de impotência diante de situações de problemática extrema, como a desses indígenas.

O termo Interinstitucionalidade está sendo utilizado neste artigo para se referir a diferentes formas de colaboração e ação conjunta entre instituições. A partir do processo aqui descrito, pode ser observado que a concretização de ações realmente direcionadas para a realidade de cada povo pode partir do interesse de indivíduos, de diferentes profissões e inserções em diversos órgãos, que se encontram sensibilizados por suas questões e se articulam na construção e execução de iniciativas em conjunto. A integração de vontades, potenciais, contatos, ideias e experiências, em um formato de rede ou coletivo de profissionais, torna possível esse tipo de ação e de luta pela efetivação de projetos, programas e políticas públicas. As iniciativas podem ser simples, com uma simplificação de processos burocráticos, visando à concretização de ações transformadoras, de forma prática, mas também reflexiva, gerando construções coletivas de atuações 
de acordo com demandas, contemplando as negociações necessárias e proporcionando importantes aprendizagens mútuas.

Nesse sentido, Santos $(2011$, p. 56, 59) considera que a única forma efetiva de enfrentamento à globalização neoliberal se trata da confrontação com outro tipo de globalização, uma globalização alternativa, contra-hegemônica, a partir da articulação com forças sociais, indivíduos, coletivos organizados, organizações não governamentais, sindicatos e movimentos sociais, com um conjunto de iniciativas que aprofundem a responsabilidade social em direção ao conhecimento pluriversal. O autor destaca a importância de integrar abordagens de conhecimentos de diversos atores sociais, e fortalecer a interlocução entre Institutos de Ensino Superior e sociedade, de um modo direcionado para a resolução de problemas locais e a formação de redes maiores de colaboração e construção de conhecimento. O trabalho em questão pode ser considerado um pequeno exemplo dessa sugestão de Boaventura Souza Santos, com a formação de uma rede de ação e reflexão, a partir da integração entre um projeto de extensão de uma IES e instituições governamentais e não governamentais, com a participação de professores/as de diversas regiões do país e também do exterior.

\subsection{Interculturalidade e Interetnicidade}

A interculturalidade é um aspecto de grande importância para a escola indígena diferenciada, na forma de um diálogo de saberes, com base na valorização simétrica e complementaridade entre conhecimentos, que contribua efetivamente para a aprendizagem de elementos de diferentes culturas, tendo em vista o alcance do duplo objetivo dessa instituição, de valorização da identidade indígena e qualificação para a relação com a sociedade ocidental. Maher (2006, p. 27) apresenta a interculturalidade como alicerce da escola indígena, o que justifica a sua existência e funcionamento. No entanto essa questão ainda constitui um importante desafio. Weigel (2000, p. 34) utiliza a metáfora escola/ maloka para abordar a situação de contraste estabelecida na instituição escolar dos povos Baniwa do alto rio Negro, um espaço de negociações entre forças sociais e culturas em condições assimétricas.

A formação de professores indígenas representa relevante papel na contribuição para enfrentar esse desafio, pois constitui uma base de preparo 
desses professores, com oportunidades de reflexão, trocas de experiências e produção de materiais. Mas assim como a escola indígena diferenciada, a formação também é um campo em construção no qual a interculturalidade enfrenta dificuldades.

O exemplo da formação continuada que é base para esta discussão apresenta um enfoque de valorização cultural e étnica, ao mesmo tempo em que oferece instrumentalização para facilitar o acesso à sociedade ocidental. Constitui um processo que coloca em evidência saberes, experiências, línguas, mitos, territórios, memórias e histórico desses povos, de modo integrado com conhecimentos ocidentais necessários para sua relação com a cidade e nas reivindicações de seus direitos.

Portanto interculturalidade e interetnicidade representaram grande importância para o desenvolvimento do trabalho, considerando que a formação de professores indígenas precisa ser intercultural, a fim de capacitar para a concretização de escolas realmente interculturais. Profissionais indígenas e não indígenas participaram da construção e desenvolvimento do curso, de diferentes formas. Além da atuação como integrantes das instituições parceiras, representantes indígenas de diferentes etnias foram convidados na condição de formadores. Esse envolvimento foi muito relevante, pois proporcionou trocas de saberes e experiências entre etnias e melhor compreensão dos temas abordados, devido à maior facilidade de acesso aos participantes, considerando suas afinidades. Além disso, a complementaridade dos conhecimentos entre diferentes culturas foi muito útil para o desenvolvimento de um curso adequado às reais necessidades dessas comunidades.

No eixo temático "Pedagogia Intercultural", tópico "Elementos para uma Educação Escolar Diferenciada", foram apresentados exemplos de escolas indígenas diferenciadas de outras etnias brasileiras, através de filmes e imagens. Também houve a participação do professor indígena André Baniwa, com apresentação do histórico do processo de construção da Escola Indígena Baniwa Coripaco Pamaáli, reconhecida como instituição de referência para inovação e criatividade na Educação Básica, pelo Ministério da Educação.

Outra participação importante foi de lideranças indígenas, em relação ao tema "Direitos, Lutas e Movimentos", em que, além de apresentações de filmes e discussões, houve a fala de líderes das etnias Nadawhup (femininas e masculinas), 
contando sobre sua atuação no movimento indígena. Também participaram representações de outras etnias, narrando sobre o movimento indígena e suas trajetórias como lideranças.

Esse aspecto tende a contribuir para o fortalecimento do potencial das escolas para a formação de lideranças, incentivando a representação nos processos organizativos indígenas e a articulação com representantes das outras etnias. Segundo Luciano (2013), um dos motivos da busca pela formação escolar no alto rio Negro está relacionado com a demanda por um maior empoderamento sociopolítico indígena. A escola é vista como oportunidade de construção da autonomia, e de fortalecimento e formação de novas de lideranças.

Grupioni e Kahn (2013) indicam o trabalho da educação escolar indígena como de fundamental importância para a formação de lideranças que passaram a assumir papéis relevantes na consolidação dos direitos de seus povos e na concretização de atividades estratégicas para a sustentabilidade de suas comunidades. Mas, para que isso ocorra, são necessários processos formativos para professores indígenas que contribuam com a formação de lideranças e de multiplicadores. Para os povos de recente contato, é importante criar uma cultura de representação, de modo a contribuir para o empoderamento e fortalecimento de lideranças, estimulando reuniões, divisão de tarefas e organização, com formação continuada e assessoria antropológica e pedagógica, auxiliando na mediação com instituições.

Nesse sentido, a noção de interculturalidade que acompanhou esse processo de formação de professores/as indígenas, e que está sendo proposta nessa reflexão, se fundamenta na perspectiva da interculturalidade crítica, no sentido atribuído por Walsh (2010), como processo contínuo de negociação, construído como projeto político, ético, social e epistêmico que afirma a necessidade de transformação nas estruturas e relações de poder que alimentam a desigualdade, discriminação e dominação.

\subsection{Interdisciplinaridade}

Interdisciplinaridade foi outro elemento muito importante nesse processo, se destacando a conjunção e integração entre diferentes áreas de conhecimento, como pedagogia, antropologia, linguística, matemática, assistência social, letras e economia. A noção de interdisciplinaridade dentro desse trabalho se inspira no 
pensamento de Fazenda (2008, p. 13), com sua visão de confluência entre diferentes áreas, projetos, conhecimentos e ideias, com as necessárias negociações, para o enfrentamento das questões globais impostas pela sociedade.

Pode ser ressaltada, de modo mais específico, a relação entre antropologia e educação, pois o trabalho não poderia ter sido desenvolvido nesse formato sem o diálogo entre esses dois campos de conhecimento. O saber e o olhar dos antropólogos participantes foram fundamentais, pelos vínculos construídos com representantes dessas etnias, através da convivência de longos períodos nas comunidades, em diversos tipos de situações, gerando aprendizagens mútuas, aproximação e intimidade, incluindo fortes laços afetivos. Além disso, com o conhecimento mais profundo e detalhado dos seus modos de vida, hábitos, mitos, visões de mundo, organização social e demandas.

A participação antropológica ocorreu desde a idealização do projeto, a construção das etapas, atividades, programação e estrutura. Essa contribuição trouxe algumas características importantes, como a perspectiva comunitária e inter-geracional, com a presença das famílias dos/as professores/as, incluindo crianças e anciãos; o calendário direcionado para períodos em que necessitam de apoio na cidade; o local do curso na maloca da FOIRN, uma construção típica indígena, de modo que eles conseguiam se sentir mais à vontade; o empenho para a tradução nas diferentes línguas; e características da alimentação, incluindo o oferecimento de chibé ao longo das atividades, uma bebida produzida com mistura de farinha de mandioca e água, que faz parte do cotidiano indígena no alto rio Negro.

Além disso, precisa ser salientada a cooperação de antropólogos na condição de formadores. No eixo temático "Pluralidade Cultural" houve a atuação do antropólogo Danilo Paiva (Universidade de São Paulo), com apresentação de imagens de caminhadas realizadas nas comunidades, expondo a importância da relação da escola com elementos culturais, como lugares sagrados, caminhos, histórias, plantas medicinais e outras peculiaridades tradicionais. Nesse tema, houve ainda a exibição de filme produzido pelo antropólogo Renato Athias (Universidade Federal de Pernambuco), especialmente para o curso, com imagens Hupd'äh de 1978, mostrando a relevância da historicidade dessas etnias e dos seus conhecimentos tradicionais. E no eixo temático "Terra, Conservação da Biodiversidade 
e Auto-sustentação" foi abordada a relação entre a escola e o Plano de Gestão Territorial e Ambiental (PGTA), através o antropólogo Danilo Paiva, apresentando os princípios do PGTA, mostrando imagens de oficinas desenvolvidas com comunidades dessas etnias, com os resultados das decisões de cada comunidade, além da condução de dinâmica de grupo de construção de mapas das áreas.

Também deve ser destacada a essencialidade da fundamentação pedagógica, no que tange a aspectos como métodos de alfabetização, construção metodológica, elaboração de materiais, legislação da educação escolar indígena e mediação entre a construção de propostas de escolas indígenas diferenciadas e exigências dos órgãos governamentais. O eixo temático "Pedagogia Intercultural" apresentou uma série de elementos importantes nesse sentido, como levantamento das demandas das escolas dessas etnias, através da reflexão em grupos; apresentação das reivindicações à representante da Secretária da Educação (SEMEC), com discussão, perspectivas e encaminhamentos; exposição de aspectos da Legislação da Educação Escolar Indígena; realização de atividades de reflexão sobre a utilização de espaços, materiais e métodos pedagógicos diferenciados; e discussão sobre construção curricular, abordando a relação entre Áreas de Conhecimento e Temas Transversais propostos no Referencial Curricular Nacional para as Escolas Indígenas (BRASIL, 1988).

Desse modo, foi observada uma importante complementaridade entre os campos de conhecimento da educação e da antropologia. Essa visão de reciprocidade, em que ambas as áreas trazem contribuições mútuas, é apresentada por Rocha e Tosta (2009, p. 17), autoras que destacam a importância da prática antropológica para um bom processo pedagógico. No entanto existem problematizações sobre a relação entre esses saberes, como no caso de Valente (1996, p. 54), que manifesta preocupação quanto à popularidade do uso de métodos de pesquisa antropológica em outras áreas de conhecimento, principalmente no campo educacional.

Através deste trabalho pode ser destacada a relevância da integração entre abordagens antropológicas e educacionais em projetos de formação de professores indígenas. Para a antropologia, o olhar e a prática educacional reforçam a visão da cultura como um processo contínuo de construção e transformação, que comporta desejos e potenciais de mudança, em que podem ser oferecidos 
contextos de alteração da situação atual, de acordo com as demandas apresentadas e com a devida consideração à vontade e ao ritmo das pessoas envolvidas, em um objetivo de melhoria da qualidade de vida nas suas diversas dimensões. Em relação à educação, elementos antropológicos trazem a essencialidade de uma atitude pedagógica de abertura para o reconhecimento e compreensão de diferentes visões de mundo, proporcionando um conhecimento mais profundo das pessoas, a quebra de estereótipos e de visões cristalizadas, e uma verdadeira valorização de diferentes modos de ser, estar, pensar e agir.

Para Dauster (2003, p. 24), os contatos com referenciais antropológicos possibilitam ao educador a apreensão de outra linguagem, com um modo diverso de olhar, se posicionar e se relacionar, proporcionando o levantamento de diferentes questões e interpretações a cerca dos fenômenos educacionais. A autora se refere às distâncias existentes entre essas duas áreas de conhecimento, com relação a referenciais, métodos e objetivos; mas valoriza suas proximidades, apostando na construção de pontes como forma de enriquecimento de ambas as áreas.

Além da antropologia e da pedagogia, outro campo de grande relevância para o desenvolvimento dessa formação se refere à linguística. Athias (2010) relata que, no processo de avaliação da terceira etapa do Curso de Magistério específico das etnias Nadawhup, alguns indivíduos Hupd'äh manifestaram a satisfação de poder escrever e ter livros escritos na sua própria língua. No entanto também afirmaram a dificuldade de avançar mais pela falta de textos na língua e de práticas de leitura; e que o português não fornece elementos gramaticais suficientes para que o exercício de tradução aconteça com relação a determinados aspectos de sua cultura. Para contribuição com essas questões na formação, houve a participação da linguista Patience Apps, da Universidade do Texas, pesquisadora dessas etnias, com atividades para discussões e construções sobre as dificuldades e os diferentes modos de escrever nas suas línguas.

A área da linguística também foi importante no Eixo Temático "Alfabetização, Letramento e Literatura Multilíngue", no qual houve a reflexão sobre gêneros literários e narrativas mitológicas da região, com atividades de construção de materiais didáticos bilíngues ilustrados, como recursos para leitura e alfabetização. E a questão linguística esteve presente ainda no eixo temático "Etnomatemática, Matemática e Numeramento", onde ocorreu a apresentação de possibilidades de 
práticas escolares no ensino da matemática na língua materna, e atividades de grupo para a construção de materiais matemáticos bilíngues, de forma integrada a componentes culturais das respectivas etnias e elementos da natureza.

O eixo temático "Educação e relação com sociedade" teve a participação de profissionais da área da antropologia, assistência social e economia, além de representantes de instituições de São Gabriel da Cachoeira, com informações sobre o funcionamento de cada instituição e os procedimentos necessários para providenciar documentações e encaminhamentos de benefícios sociais e aposentadorias. A atuação de um economista foi de grande importância, oferecendo esclarecimento de dúvidas sobre empréstimos, juros e limites do cartão bancário. A interdisciplinaridade também revelou sua grande importância nesse eixo, de modo a contribuir para que professores/as possam atuar como facilitadores/as da relação entre as comunidades e a sociedade, além de formadores/as de opinião, promovendo a consciência política, social e ambiental.

\section{CONSIDERAÇÕES FINAIS}

As particularidades de etnias de recente contato, com a gravidade de uma situação de extrema dificuldade de relação com o meio urbano, sem preparação e orientação adequadas, exigem o empenho de um conjunto de instituições, áreas de conhecimento e profissionais indígenas e não indígenas. O desenvolvimento de uma proposta de formação continuada de professores indígenas, em um formato interdisciplinar, intercultural e interinstitucional, mostra a importância desses aspectos para uma construção programática, metodológica e estrutural que realmente atenda às demandas de cada etnia e comunidade.

Os termos interdisciplinaridade, interculturalidade e interinstitucionalidade aqui abordados se referem a noções em construção que contemplam a conjunção entre diferentes culturas, saberes, pensamentos, olhares, modos de atuar e papéis institucionais na direção da resolução de questões emergentes, tendo em vista seus contextos, causas e prováveis consequências. Portanto, não podem estar desvinculadas das múltiplas dimensões necessárias ao funcionamento de uma sociedade, como política, economia, cultura, arte, espiritualidade, saúde e educação.

Dentro dessa concepção, essas noções apontam para uma diversidade de composições de possibilidades em processos construtivos contínuos, de forma 
criativa, ativa e reflexiva, oferecendo elementos relevantes para a criação de abordagens teóricas e práticas no campo da formação de professores, principalmente no que se refere ao público indígena, devido a suas especificidades.

Portanto destaca-se a importância de processos interculturais, interdisciplinares e interinstitucionais de formação continuada de professores/as indígenas, integrados a projetos de pesquisa, para que possam ser construídos e experimentados coletivamente métodos e materiais pedagógicos diferenciados, através de ações que correspondam a demandas concretas, em uma perspectiva de pesquisa engajada, de modo a propiciar contribuições efetivas para as comunidades. Esse tipo de processo proporciona dupla colaboração, tanto através da ação educacional, como pela dimensão investigativa, possibilitando reflexões sobre diferentes abordagens metodológicas e estratégias de formação de professores/as indígenas, que tanto podem ser específicas para determinadas etnias e regiões, como com potencialidades de intercâmbio e experimentação em outras realidades.

Dentre as potencialidades encontradas nessa atuação coletiva, podem ser ressaltados aspectos como uso de métodos diversificados, conexão entre teoria e prática, construção de materiais didáticos como estratégia de ensino aprendizagem, integração com atividades artísticas e culturais, uso de abordagens participativas e relação entre escola e demandas comunitárias, como a construção do PGTA.

Um dos grandes desafios desse tipo de trabalho se refere a uma construção intercultural que contribua para a valorização e o fortalecimento dos saberes e tradições indígenas, ao mesmo tempo em que ofereça preparação adequada para lidar com as exigências impostas por nossa sociedade, como documentações, burocracias, relações com instituições e sistema monetário. A questão abrange muitas dimensões que precisam ser trabalhadas, como política, economia, saúde, ambiente, cultura e educação. Torna-se necessária a construção de redes de apoio, envolvendo diversas instituições e um conjunto de conhecimentos tradicionais e técnico-científicos de diferentes áreas de conhecimento, para trabalhar nas múltiplas dimensões. A investigação revela um destaque para a relação entre antropologia e educação, cujo diálogo oferece contribuições importantes para a construção e o desenvolvimento de propostas educacionais como essa. 


\section{REFERÊNCIAS}

ATHIAS, Renato. Oralidade e prática de ensino entre os professores Hupda da região do Alto Rio Negro. In: ENCONTRO NACIONAL DE DIDÁTICA E PRÁTICA DE ENSINO (ENDIPE), 15. Convergências e tensões no campo da formação e do trabalho docente: políticas e práticas educacionais. Belo Horizonte: Centro Federal de Educação Tecnológica de Minas Gerais (CEFET-MG), 2010.

ATHIAS, Renato. Territorialidade, fronteiras e relações interétnicas na bacia do rio Uaupés. In: MARTINS, Paulo Henrique; MEDEIROS, Rogério de Souza (Org.). América Latina e Brasil em perspectiva. Recife: Alas/Editora UFPE, 2009. p. 133-68.

BARRETTO FILHO, Henyo (Org.). Formação avançada indígena do Rio Negro: resultado do processo de consulta realizado entre 2009 e 2012. São Paulo: Instituto Arapyaú, 2012. 98 p.

BRASIL. Ministério da Educação e do Desporto, Secretaria de Ensino Fundamental. Referenciais Curriculares Nacionais para as Escolas Indígenas. Brasília: MEC/SEF, 1988.

CABALZAR, Aloísio; RICARDO, Carlos Alberto. Mapa-livro povos indígenas do alto e médio rio Negro: uma introdução à diversidade cultural e ambiental do noroeste da Amazônia brasileira. São Paulo: Instituto Socioambiental; São Gabriel da Cachoeira, AM: Federação das Organizações Indígenas do Alto Rio Negro, 1998. 129p.

DAUSTER, Tania. Um saber de fronteira: entre a Antropologia e a Educação. Trabalho apresentado na Mesa Redonda: As Ciências Sociais e a Pesquisa em Educação. In: REUNIÃO ANUAL DA ANPED, 26., Poços de Caldas, outubro 2003.

ENGEL, Guido Irineu. Pesquisa-ação. Educar em Revista, Curitiba, PR, n. 16, p. 181-91, 2000.

EPPS, Patience. A grammar of Hup. 2005. 799f. Tese (Doutorado em Antropologia) University of Virginia, Charlottesville, Virginia, EUA, 2005.

FAZENDA, Ivani. A interdisciplinaridade e os saberes a ensinar: que compatibilidade existe entre esses dois atributos? À guisa de apresentação. In: FAZENDA, Ivani (Org.). O que é interdisciplinaridade? São Paulo: Cortez, 2008. p. 11-5.

FUNAI. Plano Plurianual 2012-2015. Programa de proteção e promoção dos direitos dos povos indígenas. 2012. Disponível em: http://www.funai.gov.br/arquivos/conteudo/ouvidoria/ pdf/acesso-a-informacao/Plano_plurianual-PPA_2012-2015.pdf. Acesso em: 17 ago. 2018.

GRUPIONI, Benzi; KAHN, Marina (Org.). Gestão territorial e ambiental em terras indígenas na Amazônia brasileira: os percursos da Rede de Cooperação Alternativa (RCA). São Paulo: lepé, 2013. 140p. 
Reflexões sobre interdisciplinaridade, interculturalidade e interinstitucionalidade em processo formativo de professores indígenas

LASMAR, Cristiane. De volta ao Lago de Leite: gênero e transformação no Alto Rio Negro. São Paulo: Editora UNESP/ISA; Rio de Janeiro: NUTI, 2005. 285 p.

LIMA, Ana Paula; MARQUES, Bruno; RAMOS, Danilo; FELIPE, Henrique Junio; LOLLI, Pedro; MOREIRA, Rafael. Violações de direitos de povos indígenas de recente contato: o caso dos Hupd'äh e dos Yuhupdëh da região do Alto Rio Negro (AM). ARACÊ - Direitos Humanos em Revista, [S.I.], v. 3, n. 4, p 213-26, fev. 2016.

LUCIANO, Gersem José dos Santos. Educação para o manejo do mundo: entre a escola ideal e a escola real no alto rio Negro. Rio de Janeiro: Contra Capa/Laced, 2013. 229p.

MAHER, Terezinha Machado. Formação de professores indígenas: uma discussão introdutória. In: GRUPIONI, Luís Donisete Benzi (Org.). Formação de professores indígenas: repensando a trajetória. Brasília: Ministério da Educação, Secretaria de Educação Continuada, Alfabetização e Diversidade, 2006.

MARQUES, Bruno Ribeiro. Os Hupd'ah e seus mundos possíveis: transformação espaçotemporal do Alto Rio Negro. 2015. 265 f. Tese (Doutorado em Antropologia Social) - Programa de Pós-Graduação em Antropologia Socialm Museu Nacional (PPGAS-MN), Universidade Federal do Rio de Janeiro (UFRJ), Rio de Janeiro, 2015.

MARQUES, Bruno Ribeiro. Figuras do movimento: os Hupd'ah na literatura etnológica do Alto Rio Negro. 2009. 192 f. Dissertação (Mestrado em Antropologia Social)- Programa de Pós-Graduação em Antropologia Social, Museu Nacional (PPGAS-MN), Universidade Federal do Rio de Janeiro (UFRJ), Rio de Janeiro, 2009.

MONTEIRO, Lirian Ribeiro; McLLUM, Cecília Anne. A noção de "bem viver" hupd'äh em seu território. Mundo Amazônico, [S.I.], v. 4, 2013. P.31-56.

MONTEIRO, Lirian Ribeiro. Territorialidade e mobilidade: estudo etnográfico de um grupo local Hupd äh do médio Tiquié, Amazonas. 2011. 166 f. Dissertação (Mestrado em Antropologia)- Programa de Pós-Graduação em Antropologia, Universidade Federal da Bahia (UFBA), Salvador, 2011.

MONTEIRO, Lirian Ribeiro. Breve avaliação do processo de educação escolar Hupd'äh no âmbito do projeto Saúde e Educação entre os Hupd'äh. In: ATHIAS, Renato (Org.). Ações indigenistas e experiências de intervenção entre os Hupd'äh do alto rio Negro. Recife: Editora UFPE, 2010. p. 87-100.

PAIVA, Danilo. Diagnóstico situacional participativo entre os Hupd'äh. In: ATHIAS, Renato 
(Org.). Ações indigenistas e experiências de intervenção entre os Hupd'äh do alto rio Negro. Recife: Editora UFPE, 2010. p. 35-79.

RAMIREZ, Henri. A língua dos Hupd'äh do alto Rio Negro: dicionário e guia de conversação. São Paulo: Associação Saúde Sem Limites, 2006. 272p.

ROCHA, Gilmar; TOSTA, Sandra Pereira. Antropologia \& educação. Belo Horizonte: Autêntica, 2009.

SANTOS, Boaventura de Sousa. A universidade no século XXI: para uma reforma democrática e emancipatória da universidade. São Paulo: Cortez, 2011.

SILVA, Rafael Moreira Serra da. Signos de pobreza: uma etnografia dos Hupd'äh e dos benefícios sociais no alto rio Negro. 2017. 254 f. Dissertação (Mestrado em Antropologia Social) - Programa de Pós-Graduação em Antropologia Social, Departamento de Antropologia, Centro de Filosofia e Ciências Humanas (PPGAS), Universidade Federal de Santa Catarina (UFSC), Florianópolis, 2017.

SILVERWOOD-COPE, Peter. Os Makú: povo caçador do noroeste da Amazônia. Brasília: Editora da Universidade de Brasília, 1990. 205p.

VALENTE, Ana Lúcia. Usos e abusos da antropologia na pesquisa educacional. Pro-Posições, Campinas, SP, v. 7, n. 2, p 54-64, jul. 1996.

WALSH, Catherine. Interculturalidad crítica y educación intercultural. In: VIAÑA, Jorge; TAPIA, Luis; WALSH, Catherine. (Org.). Construyendo interculturalidad crítica. La Paz: Instituto Internacional de Integración del Convenio Andrés Bello, 2010. p. 75-96.

WEIGEL, Valéria Augusta de Medeiros. Escolas de branco em maloka de índio. Manaus: Editora da Universidade do Amazonas, 2000. 375p.

\section{Sobre a autora:}

Beatriz Osorio Stumpf: Doutoranda em Educação na Universidade de Santa Cruz do Sul (UNISC). Mestre em Educação. Pedagoga. Membro do Grupo de Pesquisa Peabiru: Educação Ameríndia e Interculturalidade, do Programa de Pós-Graduação em Educação (PPGEDU) da Universidade Federal do Rio Grande do Sul (UFRGS). E-mail: beatriz.osoriostumpf@yahoo.com.br

Recebido em 20 de agosto de 2018.

Aprovado para publicação em 5 de novembro de 2018. 